\title{
Spatial distribution of the Human T-Lymphotropic Virus types I and II (HTLV-I/II) infection among blood donors of Hemominas Foundation, Belo Horizonte, Minas Gerais State, Brazil, 1994-1996
}

Mônica Silva Monteiro-de-Castro 1

Renato Martins Assunção 2

Fernando Augusto Proietti 3

\author{
Distribuição espacial da infecção pelo vírus \\ linfotrópico-T humano tipos I e II (HTLV-I/II) entre \\ doadores de sangue da Fundação Hemominas, \\ Belo Horizonte, Minas Gerais, Brasil, 1994-1996
}

1 Departamento de Epidemiologia e Métodos Quantitativos em Saúde, Escola Nacional de Saúde Pública, Fundação Oswaldo Cruz. Rua Leopoldo Bulhões 1480, Rio de Janeiro, $R J$ 21045-900, Brasil.

2 Departamento de Estatística, Instituto de Ciências Exatas, Universidade Federal de Minas Gerais. C. P. 702 , Belo Horizonte, $M G$ 30.161-970, Brasil.

3 Departamento de Medicina

Preventiva e Social, Faculdade de Medicina, Universidade Federal de Minas Gerais. Av. Alfredo Balena 190 Belo Horizonte, $M G$ 30130-100, Brasil.

\begin{abstract}
We conducted a cross-sectional study of the spatial distribution of HTLV-I/II infection among blood donors of Hemominas Foundation, living in Belo Horizonte, from 1994 to 1996. Study population $(1,022)$ was composed by 533 cases (positive Western Blot (WB), indeterminate WB and ELISA positive without WB result) and a random sample of 489 non-cases (HTLV-I/II serum negative). Cases and non-cases were georeferenced using the exact or an approximation of the household address reported at the blood donation interview. Using multivariate analysis, cases with WB result are less likely to be reposition blood donors compared to voluntary ones (OR = 0.70; CI 95\%: 0.50-0.99). Using the difference between univariate $\mathrm{K}$ functions, we found no evidence that cases and non-cases differ in their spatial distribution. We found no evidence that cases with and without WB result differ in the distance between their residence and Hemominas Foundation. No donors without WB result were georeferenced by the exact address. These donors could not have received the Hemominas letter inviting them to return to collect the second blood sample.
\end{abstract}

Key words Spatial Analysis; Spatial Distribution; HTLV-I; HTLV-II

Resumo O objetivo deste estudo seccional foi analisar a distribuição espacial da infecção pelo HTLV-I/II, em doadores de sangue da Fundação Hemominas, residentes em Belo Horizonte, de 1994 a 1996. Foram estudados 1.022 doadores, 533 casos e 489 não casos. Os casos foram estratificados em Western Blot (WB) positivos, WB indeterminados e ELISA positivos sem resultados do WB. Os casos e os não casos foram georreferenciados pelo endereço residencial exato ou por uma aproximação do mesmo. Os casos com resultado do WB menos freqüente eram dos doadores de reposição em relação a doadores voluntários (OR=0,70; IC 95\%: 0,50-0,99). Através da diferença entre as funções $\mathrm{K}$ univariadas, não há evidências de que casos e não casos difiram em relação à distribuição espacial. Os casos com e sem WB não diferiram entre si com relação à distância da Hemominas. Verificou-se que nenhum dos doadores sem resultado da segunda amostra foi georreferenciado pelo endereço exato. Esses doadores poderiam não ter retornado para coleta da segunda amostra de sangue por não terem recebido a convocação da Hemominas, que é feita por carta.

Palavras-chave Análise Espacial; Distribuição Espacial; HTLV-I; HTLV-II 


\section{Introduction and objectives}

The Human T-Lymphotropic Virus types I and II (HTLV-I/II) are human retroviruses initially described in the early eighties (Kalyanaraman et al., 1982; Poiesz et al., 1980; Yoshida et al., 1982). HTLV-I is endemic in Japan, Caribbean, Africa, South America (including Brazil) and Melanesian islands. HTLV-II has been found among injection drug users (IDU) in South, Central, and North America, Europe and Southeast Asia; among American native populations (Hall et al., 1996; Maloney et al., 1992) and among African pygmies (Delaporte et al., 1991; Froment et al., 1993; Goubau et al., 1992).

It has been estimated that between 15 to 20 million people are HTLV-I infected in the world and around 1 to $5 \%$ of these individuals eventually develop some disease related to the virus (Zaninovic, 1996). Three human diseases are associated to HTLV-I infection: adult T-cell leukemia/lymphoma (ATL), tropical spastic paraparesis/HTLV-I associated myelophaty (TSP/HAM) and HTLV-I associated uveitis (HAU) (Brew \& Price, 1988; Kabayama et al., 1988; Wong-Staal \& Gallo, 1985). There is some evidence of association between HTLV-II infection and a neurological disease similar to TSP/HAM (Murphy et al., 1999). HTLV-I/II can be transmitted through breast-feeding; transfusion of infected blood products, sexual contact and contaminated injecting tools (Manns \& Blattner, 1991). In general, the latency period between infection and disease is long (Carneiro-Proietti et al., 1996).

From an epidemiological point of view, HTLV-I/II infection is characterized by: its geographical clustering, implying in spatial variation of the serum prevalence rates within areas of elevated prevalence; increase of serum prevalence with age (age effect and/or cohort effect and/or late serum conversion); higher serum prevalence among women, especially for those older than 40 years old. The increase in the age-dependent prevalence is noticeable in adolescence and the start of adult life. Among men, this increase stabilizes after 40 years old. The increase in age-dependent prevalence is larger among women because it does not stabilize after 40 years of age. The most likely explanation for this difference is the more efficient sexual transmission from men to women and the highest frequency of blood transfusions in women. The curve trend and the maximum prevalence rate depend on the region and population under study (CarneiroProietti et al., 1996; Kajiyama et al., 1986; Sarim et al., 1990; Tajima et al., 1982).
Several aspects of HTLV-I/II infection remain unclear and deserving more investigation since HTLV-I/II is a high prevalent virus in many populations, which may be introduced in new populations, and can be transmitted through blood transfusions, can cause an impairing human disease (TSP/HAM), it can be involved in other human diseases (for example, HAU), and it is a leukemia agent in humans.

In Brazil, among blood donors, the average prevalence of $0.46 \%$ was reported (Galvão-Castro et al., 1997). According to the 1996 Census (IBGE, 1997), Brazil has a population of $157,079,573$ inhabitants, so nearly 720,000 people could be infected in the whole country.

Most of the epidemiological HTLV-I/II infection studies have not dealt with spatial issues. Very few studies have looked for associations between HTLV-I/II and geographical characteristics such as the proximity of water (Miller et al., 1986); variations among municipalities in a endemic area (Tajima et al., 1987); differences between urban and rural areas (Delaporte et al., 1988); differences among high and low altitude areas (Maloney et al., 1989, 1991); birthplace and a wide range of environmental factors (Murphy et al., 1991, 1996). It was reported that, in an HTLV-I endemic Japanese municipality, a non-central area has a prevalence rate higher than all the other areas, showing that there can be prevalence variation even in small areas (Stuver et al., 1992). This study suggested that lower socioeconomic status, and consequently poor living and environmental conditions, could contribute to the infection's spread.

These reports have motivated our study of the spatial distribution of HTLV-I/II infection in Belo Horizonte, the main municipality of one of the largest Brazilian metropolitan areas. We analyzed data from blood donors from Hemominas Foundation, a governmental blood center created in 1985 and supported by Minas Gerais State government and responsible for nearly $70 \%$ of the state blood donations and $90 \%$ of Belo Horizonte blood donations.

The aim of this study is to test for the presence of HTLV-I/II infection clusters in Belo Horizonte blood donors. Additionally, we evaluate if cases that returned to Hemominas Foundation to collect a second blood sample differ from those that did not return, with respect to the distance between the case address and Hemominas Foundation. 


\section{Material and methods}

This study has a sectional case-control design. Its population consisted of all persons donating blood at Belo Horizonte Hemominas Foundation, from $1 / 1 / 1994$ to $31 / 12 / 1996$, meaning all those eligible after standardized epidemiological and clinical screening. The study protocol was approved by Hemominas Research Ethical Committee.

Reimbursement for blood donation is illegal in Brazil. Hemominas Foundation defines reposition donors as those who donate for the benefit of a specific person and defines benefit donors as those who seek some kind of nonmonetary gain from the donation, through covenants between Hemominas and other institutions (Army, Police, etc). Those who are neither reposition nor benefit donors are defined as voluntary donors (Hemominas Internal Communication 040/99). Each donor was classified at the moment of the donation in one of these three types.

The screening aims were to exclude people with risk factors for blood transmitted diseases and to avoid risky situations for both blood donors and receptors. Data about donations were obtained from the Hemominas Foundation Data Processing Center and further processed to carry out the analysis. We excluded the 70,025 repeated donations from a same donor, selecting only the last individual donation in the study period.

Belo Horizonte is located in the Brazilian Southeast. It is the largest city in a metropolitan region, with 2,091,371 inhabitants according to the 1996 count (IBGE, 1997). Due to limited availability of digital maps for other areas, we focused on Belo Horizonte City in this paper. Hence, from a total of 139,577 donors, we excluded 58,470 non-residents in Belo Horizonte, this left 81,107 donors $(58.11 \%)$. We also excluded 3,186 (3.93\%) donors with no available serologic result for HTLV-I/II and 9 donors with ELISA indeterminate without WB result, resulting in 77,912 participants. Of those, 622 $(0.80 \%)$ were considered cases: $42(0.05 \%) \mathrm{WB}$ positive, $308(0.40 \%)$ WB indeterminate and $272(0.35 \%)$ ELISA positive without WB result. As a comparison group, we selected a simple random sample of $618(0.79 \%)$ non-cases.

At Hemominas Foundation, the screening test used is ELISA (Enzyme-Linked Immunosorbent Assay), and the supplementary one is Western Blot (WB). The kits used are Vironostika HTLV-I/II Organon Teknika and HTLV Blot 2.4 Genelabs Diagnostics (or Cambridge Biotech). The ELISA is repeated three times in the same blood sample and, if at least two of three results are positive, the donor is called to collect a second sample in which the WB is done.

All cases and the random sample of noncases were geocoded and georeferenced through an address database routine used by the Belo Horizonte City Health Department. For each donor, we map his exact address, if this address is in the database. If not, we either map a close address number in the same street (if it is present in the database) or we exclude the individual from the map if no other household is found in the database near to the reported address. For the process of georeferencing, we use Belo Horizonte geographical base file maintained by the City Data Processing Department (Prodabel) which contains all addresses and their geographical coordinates. Therefore, each donor has been identified in the Belo Horizonte map by a dot at his residential address location. We analyzed this spatial data with the software InfoMap (Infomap, 1995) and S-Plus 4.5 (S-Plus, 1998).

The main reasons for no geocoding were: (a) existence of several streets with the same name in the same neighborhood; (b) existence of more than one neighborhood with the same name in the same region or in different regions of the city; (c) lack of correspondence between the neighborhood reported by the donor and that listed in the codification routine; (d) lack of georeferencing of an address, even if we obtain the correct street code. This occurred probably because of deficiencies in the street base file that has been used.

To test if Belo Horizonte has spatially homogeneous HTLV-I/II prevalence rates, we compared the spatial point patterns of cases and non-cases residences. This comparison was carried out verifying if the cases and noncases spatial distributions appear as if points are randomly labeled as cases and non-cases (Diggle, 1993), as is explained in sequence.

Suppose that there are $n$ cases and $m$ noncases represented as points in a map, and that each point receives a case or non-case label. Suppose also that each label is chosen in a completely random way with the restriction of ending up with $n$ case labels and $m$ non-case labels. Spatial point patterns labeled in this way result in configurations where the point label is independent from its location. As a consequence, the spatial distribution of the two types of points is the same. The hypothesis of random labeling is tested by the $K$ function method (Ripley, 1981).

The $K$ function is a spatial point pattern analysis technique that describes the spatial 
dependence in the point's spatial distribution and it can be used for hypothesis testing (Ripley, 1981). For each possible distance $d$, the $K$ function associates the $K(d)$ value that is proportional to the average number of events distant from an arbitrary event by at most $d$. This function can be visualized in a plot of $K(d)$ values against the associated distance $d$.

After estimating two $K$ curves, one for the cases, denoted by $K_{l}(d)$, and another for the non-cases, denoted by $K_{0}(d)$, we take the difference $K(d)=K_{l}(d)-K_{0}(d)$. If the case or noncase labeling is done completely at random, then the $K$ functions of the two groups are identical and $K(d)$ should be zero for every $d$ value. To test if the $K(d)$ observed values are significantly different from zero, confidence simulation envelopes are built (Diggle, 1993). If the $K(d)$ is situated above the upper simulation envelope, we can conclude that there are significant spatial clusters of cases in relation to what is expected considering the non-cases spatial pattern (Gatrell, 1996).

The other spatial point pattern analysis technique we used has been originally proposed to test the existence of cluster in the vicinity of fixed locations (Diggle \& Elliot, 1995; Diggle \& Rowlingson, 1994), such as an environmental pollution source or a disease dissemination focus. This technique was employed to test if WB positive and indeterminate cases tend to have a higher concentration in areas near Hemominas Foundation than ELISA positive cases. The alternative hypothesis was that the donor's chance of returning to collect the second blood sample decreases with the distance from their residence to Hemominas Foundation.

We consider the spatial density of two types of point patterns, those of WB positive and indeterminate cases and those of ELISA positive cases. Assume that the average number of cases without WB result in a small area around ( $x$, $y$ ) location is proportional to $\lambda_{0}(x, y)$. Assume also that the distance $d$ between the donor's residence and Hemominas Foundation has no effect on the chance of an ELISA positive case returning to carry out the second exam. Then the average number of WB cases around $(x, y)$ location is proportional to $\lambda_{0}(x, y)$. In the alternative case, it is modeled as

$\lambda_{1}(x, y)=\rho \lambda_{0}(x, y)\left(1+\alpha e-\beta d^{2}\right)$

The last term represents the Hemominas distance effect. If $\beta$ is positive, it decreases exponentially towards 1 and let the WB cases density $\lambda_{1}(x, y)$ to approach a level proportional to ELISA cases density $\lambda_{0}(x, y)$ as the distance $d$ increases. The parameters $\rho, \alpha$ and $\beta$ are esti- mated by the maximum likelihood method and the hypothesis test of Hemominas distance effect is based on the maximum likelihood ratio test.

\section{Results}

Initially, we compared the non-case simple random sample (618) with all the non-cases $(77,290)$ concerning the variables sex, nationality, birthplace, civil state, donation type and age. No statistically significant difference was found (Table 1).

We compared the groups with and without WB result by logistic regression: cases with WB result are less likely to be reposition blood donors compared to voluntary ones $(\mathrm{OR}=0.70$; CI 95\%: 0.50-0.99). Concerning the variables sex, nationality, birthplace, civil state and age, we did not find statistically significant differences (Table 2).

Table 3 shows the results of cases and noncases geocoding using the Prodabel addresses database. Except for the ELISA positive individuals, geocoding was quite similar in the other three categories, most of them geocoded by the exact address. No ELISA positive individuals were geocoded by their exact address and $83 \%$ was geocoded by the nearest address.

Spatial distribution of cases and non-cases can be seen in Figures 1 to 4 . Using a random labeling test, we find no evidence of spatial distribution difference between cases and noncases. In Figures 5 to 7 , we show the curves of the $\mathrm{K}$ function differences between cases and non-cases and the confidence simulation envelopes of $95 \%$ built using one hundred simulations. Since the estimated curve is inside the simulation envelope in all situations, we concluded that there is no difference in spatial configuration of cases and non-cases, and yet, that case and non-case labels has been attributed to the events in a spatially completely random way.

Concerning the distance between each case and Hemominas Foundation, we present in Figure 8, standardized to the largest observed distance, the frequency distribution of the distances for the two groups, with and without the WB result. Apparently there is no significant difference between the groups. This can be seen also in Figure 9, which shows the cumulated frequency curve for both groups.

Applying the test proposed by Diggle \& Rowlingson (1994), we found no difference between ELISA positive without WB result individuals in relation to cases with the WB result 
Univariate analysis of 77,290 non-cases from the city of Belo Horizonte and a simple random sample of $618(0.18 \%)$ non-cases selected for spatial analysis according to selected socio-demographic variables. Hemominas Foundation, 1994-1996.

\begin{tabular}{|c|c|c|c|c|c|}
\hline \multirow[t]{2}{*}{ Variable/Category } & \multicolumn{2}{|c|}{ Total } & \multicolumn{2}{|c|}{ Sample } & \multirow[t]{2}{*}{$\mathrm{p}$-value } \\
\hline & $\mathrm{n}$ & $\%$ & $\mathrm{n}$ & $\%$ & \\
\hline \multicolumn{6}{|l|}{ Sex } \\
\hline Men & 54,591 & 70.63 & 447 & 72.33 & \\
\hline Women & 22,699 & 29.37 & 171 & 27.67 & 0.36 \\
\hline \multicolumn{6}{|l|}{ Nationality } \\
\hline Other & 160 & 0.21 & 3 & 0.49 & \\
\hline Brazilian & 77,130 & 99.79 & 615 & 99.51 & 0.13 \\
\hline \multicolumn{6}{|l|}{ Birthplace } \\
\hline Other & 36,075 & 46.67 & 289 & 46.76 & \\
\hline Belo Horizonte & 37,054 & 47.94 & 298 & 48.22 & 0.96 \\
\hline $\mathrm{GMBH}$ & 4,161 & 5.38 & 31 & 5.02 & 0.70 \\
\hline \multicolumn{6}{|l|}{ Marital status* } \\
\hline Single & 40,643 & 52.60 & 330 & 53.40 & \\
\hline Married & 32,912 & 42.60 & 250 & 40.45 & 0.43 \\
\hline Other ${ }^{\star \star}$ & 3,710 & 4.80 & 38 & 6.15 & 0.18 \\
\hline \multicolumn{6}{|l|}{ Donation type } \\
\hline Voluntary*** & 28,023 & 36.26 & 211 & 34.14 & \\
\hline Replacement & 45,317 & 58.63 & 376 & 60.84 & 0.26 \\
\hline Benefit & 3,950 & 5.11 & 31 & 5.02 & 0.83 \\
\hline Age $e^{\star \star \star \star}$ & 30.49 & 9.30 & 30.44 & 9.13 & 0.89 \\
\hline
\end{tabular}

* totals differ because of missing values

** divorced and others

$\star \star \star$ includes invited and scheduled donations

$\star \star \star \star$ for age, median, standard error

$\mathrm{GMBH}=$ Greater Metropolitan Belo Horizonte

(positive and indeterminate). The $\mathrm{p}$-value was 0.998 meaning that the distance between the donor household and Hemominas Foundation is not associated with the individual returning to provide the second blood sample.

\section{Discussion and conclusions}

When studying human diseases, it is necessary to detect evidences of clustering beyond the underlying environmental heterogeneity. By definition, a cluster is a case concentration in a specific area beyond what was expected considering the spatial distribution of the risk population. Since the population at risk is spatially distributed in a heterogeneous way, it is expected that the cases spatial pattern in a map will also exhibit spatial heterogeneity. In our study, the Hemominas donors compose the risk population, which has an unknown spatial distribution, probably different from the total population of Belo Horizonte. Therefore, to control the donor population for spatial heterogeneity, we use the non-case sample.

We find that there is no difference in spatial configuration of cases and non-cases in Belo Horizonte City. As far as we know, this is the first analysis of HTLV-I/II spatial distribution in a Brazilian city. Since we are working with a relatively small sample of cases and non-cases, the non-significance of the results could be due to low power of the tests employed. There is no study addressing this power issue for the difference between univariate $K$ functions.

As we mentioned in the introduction, HTLV-I/II causes disease in less than $5 \%$ of the infected persons and the latency period be- 
tween infection and disease is long. Our study had a sectional design and there was no possibility of analyzing the temporal dimension of HTLV-I/II infection. So, we could not distinguish cases which were recently infected from cases that were infected long time ago. We do not know if this distinction could bring new information about the spatial distribution of the infection in Belo Horizonte.
Although we can not generalize for the whole risk population, concerning at least Hemominas Foundation blood donors, HTLV-I/II infection should be a matter of concern for the entire city and not for any specific area. Belo Horizonte is a big city; Brazilian cities in general have limited resources available for health programs; and public health actions can sometimes be very costly. As HTLV-I/II is an impor-

Table 2

Logistic regression of selected variables for 350 WB HTLV-I/II positive and indeterminate blood donors and 272 ELISA positive blood donors without results for WB. Hemominas Foundation, Belo Horizonte, 1994-1996.

\begin{tabular}{|c|c|c|c|c|}
\hline Variable/Category & With WB & Without WB & OR & $95 \% \mathrm{Cl}$ \\
\hline \multicolumn{5}{|l|}{ Sex } \\
\hline Men & 257 & 197 & 1.00 & \\
\hline Women & 93 & 75 & 0.91 & $0.63-1.31$ \\
\hline \multicolumn{5}{|l|}{ Birthplace } \\
\hline Other & 155 & 123 & 1.00 & \\
\hline $\mathrm{BH}$ & 168 & 132 & 1.07 & $0.76-1.51$ \\
\hline $\mathrm{GMBH}$ & 27 & 17 & 1.22 & $0.63-2.34$ \\
\hline \multicolumn{5}{|l|}{ Marital status } \\
\hline Single & 180 & 149 & 1.00 & \\
\hline Married & 144 & 97 & 1.15 & $0.77-1.73$ \\
\hline Other* & 26 & 26 & 0.78 & $0.40-1.51$ \\
\hline \multicolumn{5}{|l|}{ Donation type } \\
\hline Voluntary** & 128 & 80 & 1.00 & \\
\hline Replacement & 213 & 185 & 0.70 & $0.50-0.99$ \\
\hline Benefit & 9 & 7 & 0.86 & $0.31-2.43$ \\
\hline Age & 31.19 & 30.35 & 1.01 & $0.99-1.03$ \\
\hline
\end{tabular}

$\mathrm{OR}=1.00$ is the reference category; $\mathrm{WB}=$ Western blot; $\mathrm{GMBH}=$ Greater Metropolitan Belo Horizonte. * divorced and others

** includes invited and scheduled donations

Table 3

Results of geocoding of case and non-case individuals by reported address.

Hemominas Foundation, Belo Horizonte, 1994-1996.

\begin{tabular}{lrrrr} 
& WB positive & WB indeterminate & ELISA positive & Non-Cases \\
\hline Exact address & $63 \%$ & $62 \%$ & $0 \%(0)$ & $71 \%$ \\
Nearest address & $25 \%$ & $26 \%$ & $83 \%(225)$ & $17 \%$ \\
No geocoding & $12 \%(5)$ & $12 \%(37)$ & $17 \%(47)$ & $12 \%(75)$ \\
Total & $100 \%(42)$ & $100 \%(308)$ & $100 \%(272)$ & $100 \%(622)$ \\
\hline
\end{tabular}

(Numbers in parenthesis are the group sizes)

WB $=$ Western Blot 


\section{Figure 1}

Spatial distribution of HTLV-I/II WB positive cases. Hemominas Foundation, Belo Horizonte, 1994-1996.

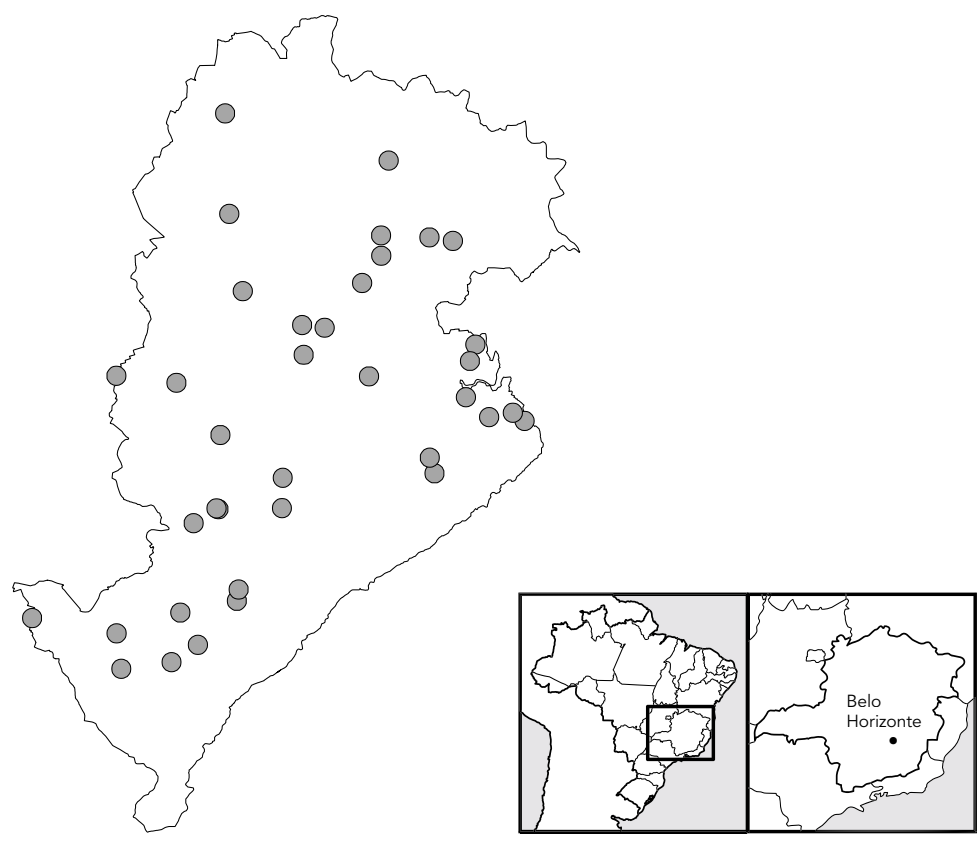

Figure 2

Spatial distribution of HTLV-I/II WB indeterminate blood donors. Hemominas Foundation, Belo Horizonte, 1994-1996.

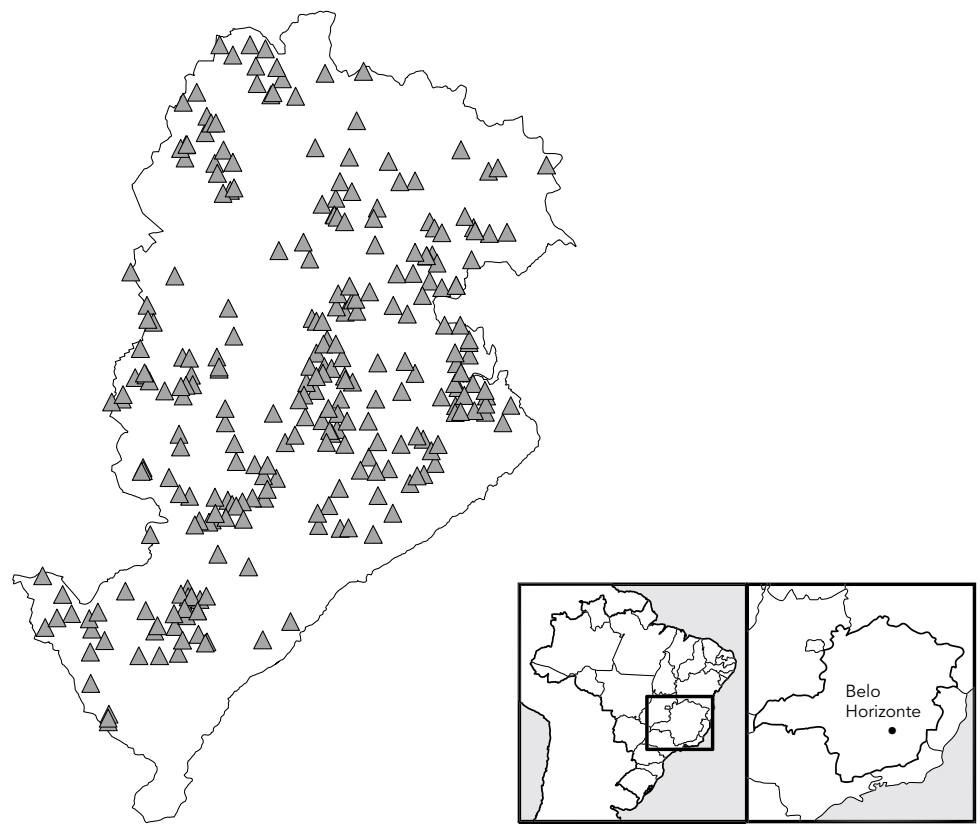




\section{Figure 3}

Spatial distribution of HTLV-I/II ELISA positive blood donors without WB result. Hemominas Foundation, Belo Horizonte, 1994-1996.

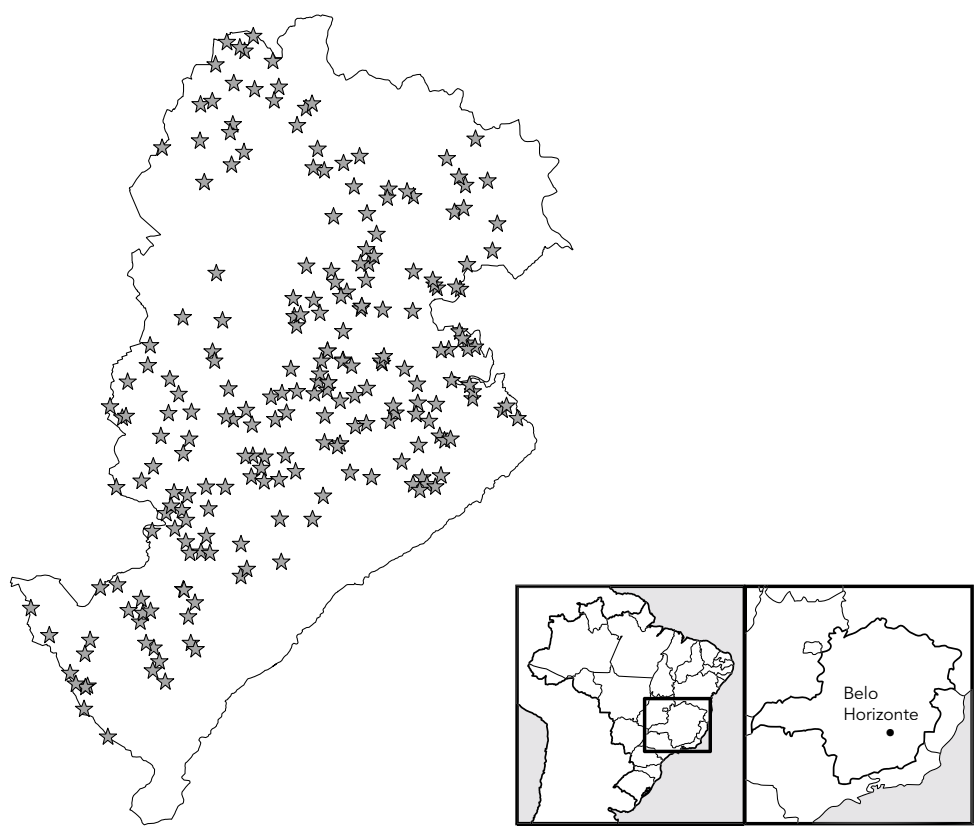

Figure 4

Spatial distribution of the selected control sample. Hemominas Foundation, Belo Horizonte, 1994-1996.

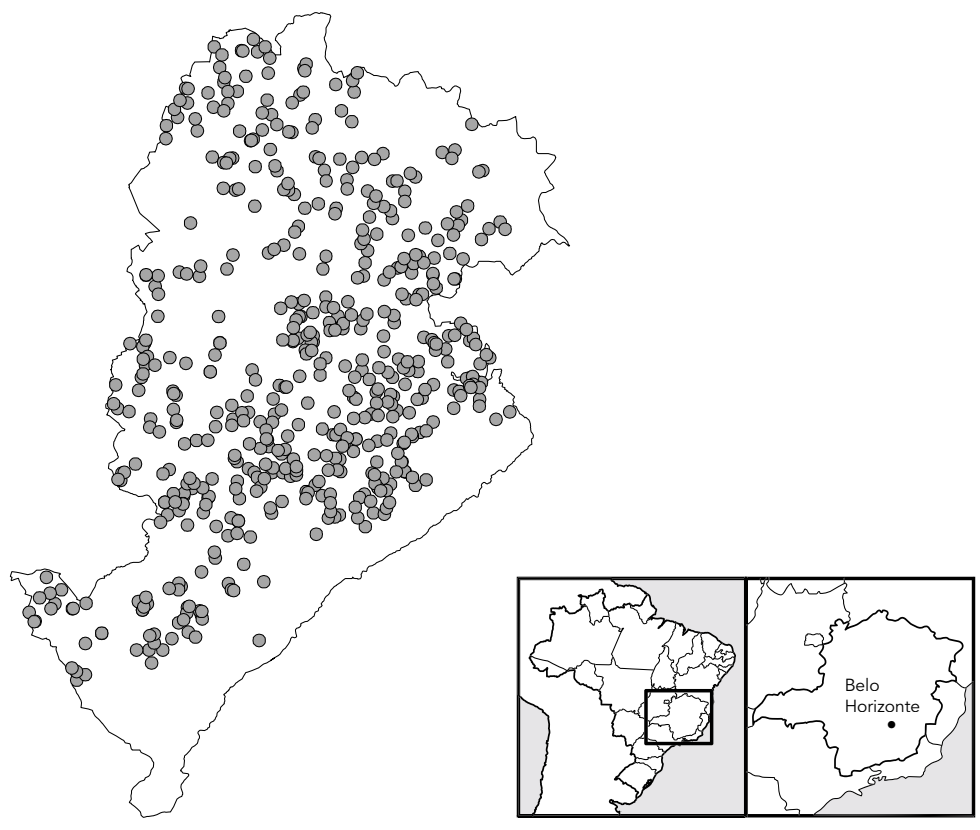


tant human pathogen, we believe that the local authorities should further discuss this subject, consider measures to advise infected people and to prevent transmission. People working with donor screening at Hemominas Foundation must keep in mind that the infection is present all over the city, and that there is not a specific risk area or population group within the city.

In another study (Monteiro-de-Castro, 1999), we hypothesized that cases that did not return to collect the second blood sample could differ from the ones that returned with respect to the distance between the current household and Hemominas Foundation. That is, cases without WB result, could not have returned because they lived far away from the Hemominas Foundation. In Belo Horizonte, as in other big cities in Brazil, people with lower social and economical conditions live in the suburbs, mainly because housing is much less expensive. On the average, they depend mostly on public transportation to the downtown area, where Hemominas Foundation is located. The ticket may be expensive and the ride may take a couple of hours. However, we did not find a significant difference between the two groups compared, with and without WB results. So, other factors may be influencing blood donors probability of returning to collect the second blood sample.

There was a significant difference between the groups considering donation type. This could mean that reposition blood donors return less frequently to collect the second sample, because they donate blood in benefit of someone close to them and they could be less interested in the serological results. Hemominas team may work with the reposition donors reinforcing the importance of completing the serological tests.

The geocoding results for the Hemominas were similar to those obtained usually by the Belo Horizonte City Health Department (BHHD). For example, using the database of the Brazilian Health Ministry Information System for Live Births (SINASC) in Belo Horizonte in 1997, which was considered of good quality, BHHD found that the geoprocessing was done by the exact address in $57.9 \%$ of the cases, by the nearest address in $29.6 \%$, and $12.5 \%$ remained with no geocoding (personal communication). These numbers are similar to our own (Table 3).

The fact that any of ELISA positive cases were geocoded by the exact address indicates a likely lack of accuracy in these donors' addresses. This group has also the highest percentage
Figure 5

Difference between univariate $\mathrm{K}$ functions for HTLV-I/II WB positive cases and selected controls. Hemominas Foundation, Belo Horizonte, 1994-1996.

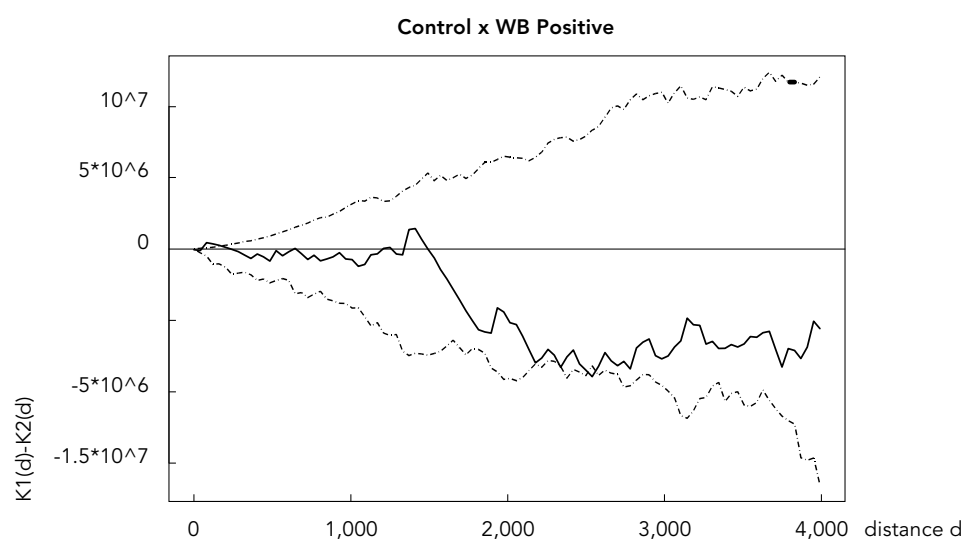

Figure 6

Difference between univariate $\mathrm{K}$ functions for HTLV-I/II WB indeterminate blood donors and selected controls. Hemominas Foundation, Belo Horizonte, 1994-1996.

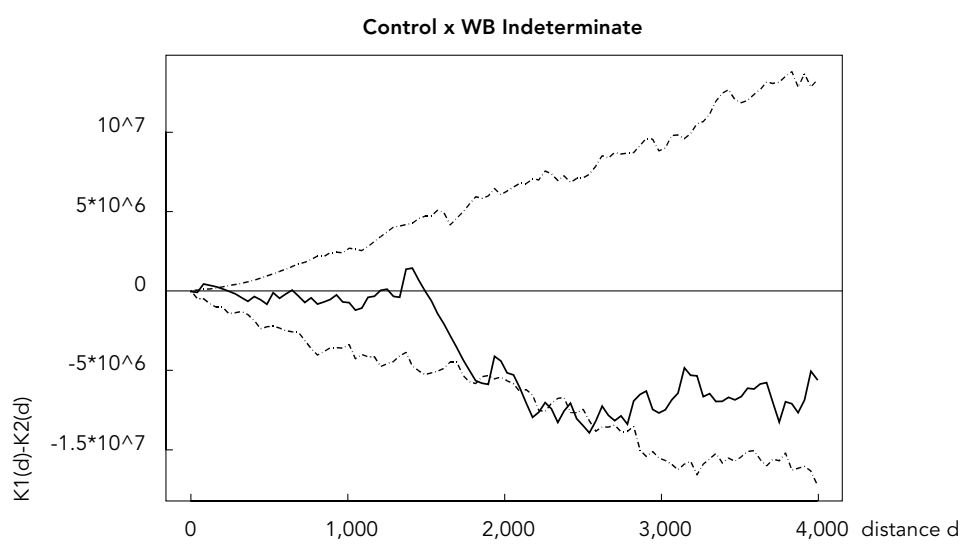

Figure 7

Difference between univariate K functions for HTLV-I/II ELISA positive blood donors without WB result and selected controls. Hemominas Foundation, Belo Horizonte, 1994-1996.

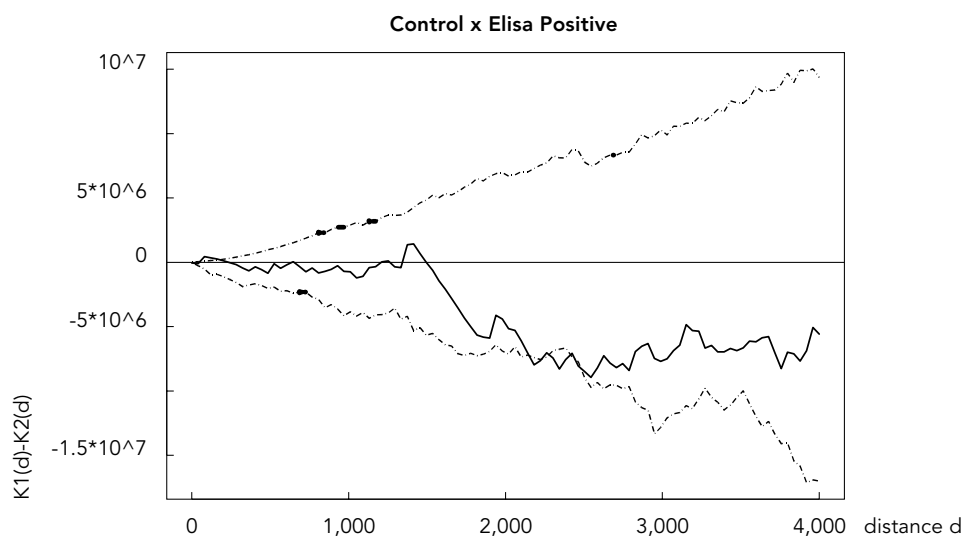


Figure 8

Frequency distribution of distance from place of residence to Hemominas Foundation, cases with and without WB result. Belo Horizonte, 1994-1996. (The distance scale is the proportion between the geographical distance and the largest observed distance).

WB positive and indeterminate

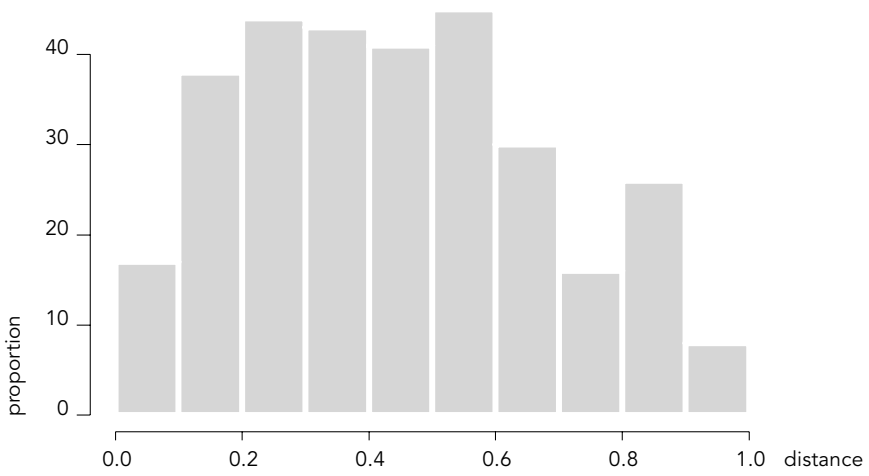

ELISA positive without WB

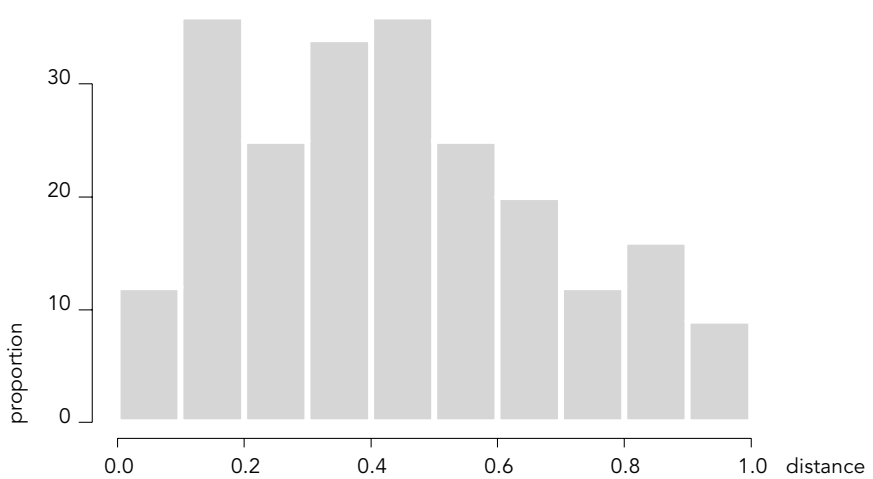

Figure 9

Cumulative distribution of distance from place of residence to Hemominas Foundation, cases with and without WB results. Belo Horizonte, 1994-1996. (The distance scale is the proportion between the geographical distance and the largest observed distance).

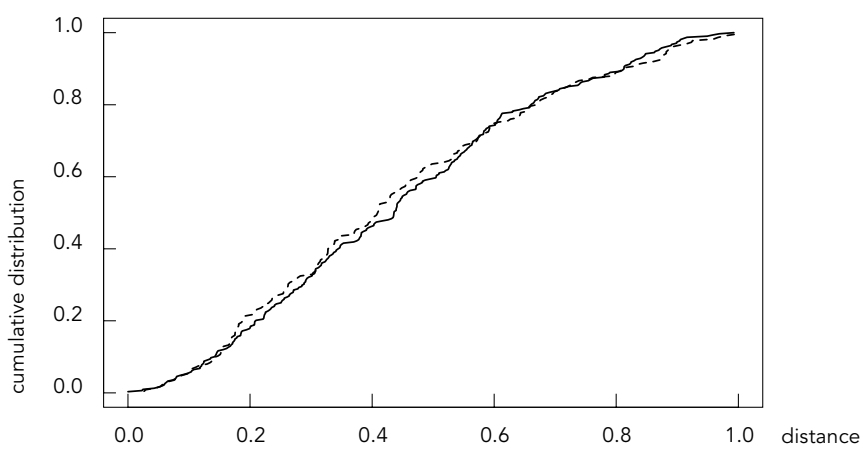

of cases not georeferenced (17.28\%). Since Hemominas Foundation usually communicates with the donors by mail, misreported addresses could explain why the donors do not return to collect the second blood sample. It is also possible that reposition blood donors engaged in high risk behavior for sexually transmitted diseases and may not report their addresses accurately, although not refusing to donate when asked to do so by family and/or friends. We believe that Hemominas Foundation should work on ways of improving address accuracy, so the donors could be contacted whenever it is necessary.

Before final conclusions are taken, we must comment on some limitations of our study. We analyzed administrative secondary data, not collected for this study objectives, and some imprecision in the registries might have occurred. We used the absence of the second blood sample result in the database as a marker for not having returned to Hemominas Foundation. However, the individual could have returned and the result was not available for some technical reasons (test not done, result not entered in database, etc). Since there was no available digital map for the entire metropolitan area (with $91 \%$ of the Hemominas donors), our study is limited to Belo Horizonte City (58\% of the donors). Unfortunately, we could not analyze the donor's socioeconomic status, since the pertinent variables were not available in a useful way or were not routinely collected at the interview.

In conclusion, we find no evidence of a distance effect from Hemominas Foundation for the chance of returning after receiving an ELISA positive result. Also, studying a large blood donor population, we find no evidence of clustering of HTLV-I/II infection in Belo Horizonte blood donors. 


\section{References}

BREW, B. J. \& PRICE, R. W., 1988. Another retroviral disease of the nervous system. Chronic progressive myelopathy due to HTLV-I. New England Journal of Medicine, 318:1195.

CARNEIRO-PROIETTI, A. B., 1996. Cadernos Hemominas: HTLV I/HTLV II. Belo Horizonte: Fundação Centro de Hematologia e Hemoterapia de Minas Gerais.

DELAPORTE, E.; DUPONT, A.; PEETERS, M.; JOSSE, R.; MERLIN, M. \& SCHRIJVERS, D., 1988. Epidemiology of HTLV-I Gabon (Western Equatorial Africa). International Journal of Cancer, 42:687689.

DELAPORTE, E.; LOUWAGIE, J.; MONTPLAISIR, N.; D'AURIOL, L.; VILLE, Y. \& BEDJABAGA, L., 1991. Evidence of HTLV-II infection in Central Africa. AIDS, 5:771-772.

DIGGLE, P. J., 1993. Point process modeling in environmental epidemiology. In: Statistics for the Environment (V. Barnett \& K. F. Turkman, ed.). Chichester: John Wiley.

DIGGLE, P. J. \& ELLIOT, P., 1995. Disease risks near point sources: Statistical issues for analysis using individual or spatially aggregated data. Journal of Epidemiology and Community Health, 49:S20S27.

DIGGLE, P. J. \& ROWLINGSON, B. S., 1994. A conditional approach to point process modeling of elevated risk. Journal of the Royal Statistical Society, Series A, 157:433-440.

FROMENT, A.; DELAPORTE, E.; DAZZA, M. \& LAROUZÉ, B., 1993. HTLV-II among Pygmies from Cameroon. AIDS Research and Human Retroviruses, 9:707.

GALVÃO-CASTRO, B.; FERREIRA Jr., O. C.; FRANCO, L. G. F.; MULLER, M.; SAMPAIO, D. A. \& SANTANA, A., 1997. Distribution of HTLV-I among blood donors: A nationwide Brazilian study. Transfusion, 37:242.

GATRELL, A. C.; BAILEY, T. C.; DIGGLE, P. J. \& ROWLINGSON, B. S., 1996. Spatial point pattern analysis and its application in geographical epidemiology. Transactions of the British Institute of Geography, 21:256-274.

GOUBAU, P.; DESMYTER, J. \& GHESQUIERE, J., 1992. HTLV-II among pygmies. Nature, 359:201.

HALL, W. W.; ISHAK, R.; ZHU, S. W.; NOVOA, P.; EIRAKU, N. \& TAKAHASHI, H., 1996. HTLV-II: Epidemiology, molecular properties, and clinical features of infection. Journal of Acquired Immune Deficiency Syndromes and Human Retrovirology, 13:S204-214.

IBGE (Fundação Instituto Brasileiro de Geografia e Estatística), 1997. Contagem de População de 1996. Rio de Janeiro: IBGE.

INFOMAP, 1995. Interactive Spatial Data Analysis, London: Longman Scientific \& Technical.

KABAYAMA, Y.; ISASHIKI, M.; UCHARA, F. \& OHBA, N., 1988. Ocular disorders associated with adult T-cell leukemia. Japanese Journal of Clinical Ophthalmology, 42:139-141.

KAJIYAMA, W.; KASHIWAGI, S.; IKEMATSU, H.; HAYASHI, J.; NOMURA, H. \& OKOCHI, K., 1986. Intra-familial transmission of adult T-cell leukemia virus. Journal of Infectious Diseases, 154:851-857.

KALYANARAMAN, V. S.; SARNGADHARAN, M. G. \& ROBERT-GUROFF, M., 1982. A new subtype of human T-cell leukemia virus (HTLV-II) associated with a T-cell variant of hairy cells leukemia. Science, 218:571-573.

MALONEY, E. M.; BIGGAR, R. J.; NEEL, J. V.; TAYLOR, M. E.; HAHN, B. H. \& SHAW, G. M., 1992. Endemic HTLV-II infection among isolated Brazilian Amerindians. Journal of Infectious Diseases, 166: 100-107.

MALONEY, E. M.; MURPHY, E. L.; FIGUEROA, J. P.; GIBBS, W. N.; CRANSTON, B. \& HANCHARD, B., 1991. HTLV-I seroprevalence in Jamaica: Geographic and ecological determinants. American Journal of Epidemiology, 133:1125-1134.

MALONEY, E. M.; RAMIREZ, H.; LEVIN, A. \& BLATTNER, W. A., 1989. A survey of HTLV-I in south western Colombia. International Journal of Cancer, 44:419-423.

MANNS, A. \& BLATTNER, W. A., 1991. The Epidemiology of the human T-cell Lymphotropic virus types I and type II: Etiologic role in human disease. Transfusion, 31:67-75.

MILLER, G. J.; PEGRAM, S. M.; KIRKWOOD, B. R.; BECKELES, G. L. A.; BYAM, N. T. A. \& CLAYDEN, S. A., 1986 Ethnic composition, age and sex, together with location and standard of housing as determinants of HTLV-I infection in a urban Trinidadian community. International Journal of Cancer, 38:801-806.

MONTEIRO-DE-CASTRO, M. S., 1999. Fatores Relacionados à Soroprevalência da Infecção pelo Vírus Linfotrópico para Células T Humanas dos Tipos I e II (HTLV-I/II) em Doadores de Sangue da Fundação Hemominas, Belo Horizonte, 1994-1996. Dissertação de Mestrado, Belo Horizonte: Faculdade de Medicina, Universidade Federal de Minas Gerais.

MURPHY, E. L.; FIGUEROA, J. P.; GIBBS, W. N.; HOLDING-COBHAM, M.; CRANSTON, B. \& MALLEY, K., 1991. HTLV-I seroprevalence in Jamaica: Demographic determinants. American Journal of Epidemiology, 133:1114-1124.

MURPHY, E. L.; WATANABE, K.; NASS, C. C.; OWNBY, H.; WILLIAMS, A. \& NEMO, G., 1999. Demographic determinants of HTLV-I and HTLV-II seroprevalence among blood donors: Evidence for a 30year old epidemic of HTLV-II in the United States. Journal of Infectious Diseases, 180:1777-1783.

MURPHY, E. L.; WILKS, R.; HANCHARD, B.; CRANSTON, B.; FIGUEROA, J. P. \& GIBBS, W. N., 1996. A case control study of risk factors for seropositivity to HTLV-I in Jamaica. International Journal of Epidemiology, 25:1083-1089.

POIESZ, B. J.; RUSCETTI, F. W.; GAZDAR, A. F.; BUNN, P. A.; MINNA, J. D. \& GALLO, R. C., 1980. Detection and isolation of type-C retrovirus particles from fresh and cultured lymphocytes of a patient with coetaneous T-cell lymphoma. Proceedings of the National Academy of Science of the United States of America, 77:7415-7419.

RIPLEY, B. D., 1981. Spatial Statistics. Chichester: John Wiley. 
SARIM, S. G.; FANG, C. \& WILLIAMS, A., 1990. Retroviral infections transmitted by blood transfusion. Yale Journal of Biology and Medicine, 63:353-360.

S-PLUS INCORPORATION, 1998. Professional [Computer Program], 4.5 Version. Seattle: MathSoft Incorporation.

STUVER, S. O.; TACHIBANA, N. \& MUELLER, N., 1992. Case-control study of factors associated with HTLV-I infection in southern Miyazaki, Japan. Journal of the National Cancer Institute, 84:867872.

TAJIMA, K.; TOMINAGA, S.; SUCHI, T.; KAWAGOE, T.; KOMODA, H. \& HINUMA, Y., 1982. Epidemiological analysis of the distribution of antibody to adult T-cells leukemia virus-associated antigen: Possible horizontal transmission of adult T-cell leukemia virus. Japanese Journal of Cancer Research, 73:893-901.
TAJIMA, K.; KAMURA, S.; ITO, S.; ITO, M.; NAGATOMO, N. \& KINOSHITA, K., 1987. Epidemiological features of HTLV-I carriers and incidence of ATL in an ATL - endemic island: A report of the community-based cooperative study in Tsushima, Japan. International Journal of Cancer, 40:741746.

WONG-STAAL, F. \& GALLO, R. C., 1985. The family of Human T-Lymphotropic Leukemia Viruses: HTLVI as the cause of adult T cell leukemia and HTLVIII as the cause of acquired immune deficiency syndrome. Blood, 65:253-268.

YOSHIDA, M.; MIYOSHI, I. \& HINUMA, Y., 1982. Isolation and characterization of retrovirus from cell lines of human adult T-cell leukemia and its implication in the disease. Proceedings of the National Academy of Science of the United States of America, 79:2031-2035.

ZANINOVIC, V., 1996. HTLV, Truths and Questions. Cali: Fundación MAR. 